\title{
North Sea saithe Pollachius virens growth in relation to food availability, density dependence and temperature
}

\author{
Cormon Xochitl ${ }^{1,{ }^{*}}$, Ernande Bruno ${ }^{1}$, Kempf Alexander ${ }^{2}$, Vermard Youen ${ }^{3}$, Marchal Paul ${ }^{1}$ \\ ${ }^{1}$ IFREMER, Channel \& North Sea Fisheries Res Unit, 150 Quai Gambetta,BP 699, F-62321 Boulogne \\ Sur Mer, France. \\ 2 Thunen Inst Sea Fisheries, Palmaille 9, D-22767 Hamburg, Germany. \\ ${ }^{3}$ IFREMER, Unit Fisheries Ecol \& Modelling, BP 21105, F-44311 Nantes 03, France. \\ *Corresponding author : Xotchitl Comron, email address : xochitl.cormon@ifremer.fr
}

\begin{abstract}
:
North Sea saithe Pollachius virens, a major top predator in the area, supports the fishery economy of several European countries. However, recent stock assessments suggested a decrease in spawning stock biomass along with a decline in saithe mean weight-at-ages. In this context, we investigated North Sea saithe growth characteristics at the population level. First, saithe annual weight increments and age-length relationships were studied. Modelling of saithe age-length relationships was carried out using (1) the traditional von Bertalanffy growth function model, (2) the Verhulst logistic model and (3) an empirical linear model. Second, the effects of environmental factors on saithe growth were investigated. Explanatory environmental factors included food availability, represented by the total biomass of Norway pout Trisopterus esmarkii; intraspecific competition, i.e. density dependence, represented by saithe abundance; and temperature. This study revealed that the Verhulst logistic model was the best descriptor of saithe growth and that density dependence and food availability had significant effects on the saithe growth coefficient, while no effect of temperature was shown. We suggest that reduced food availability and increased competition may explain the recent decrease in the saithe growth coefficient.
\end{abstract}

Keywords : Bottom-up processes, von Bertalanffy growth function, Logistic growth, Norway pout, Prey availability effects, Density-dependence, Predator-prey interactions, Resource limitation, Competition 


\section{Introduction}

Understanding factors regulating population dynamics is a cornerstone in ecology, particularly in exploited ecosystems (Frederiksen et al., 2006, Laundré et al., 2014). The size of a population is strongly influenced by its position within the trophic network to which it belongs (Cury et al., 2003) and by the productivity of the ecosystem, its carrying capacity. In heavily exploited marine ecosystems, assessing the size (biomass and/or abundance) of commercial fish stocks with a sufficient accuracy is of primary importance to support fisheries management.

In an ecosystem approach to fisheries management (FAO, 2003), multi-species stock assessment tools have been developed to better integrate trophic interactions in fisheries diagnostics (ICES, 2012). These tools generally allow the estimation of top-down effects, i.e. control exerted by predators on prey populations, through an estimation of predation mortalities, see Plaganyi (2007), section 2.2, for a review. However, the reverse effects (bottom-up), i.e. the potential regulation of predator populations through prey availability, are often not estimated despite their recognized importance (Frederiksen et al., 2006). Understanding these bottom-up processes is necessary to gain insights into interspecific competition which involves relationships through shared preys in both directions (top-down and bottom-up).

Saithe (Pollachius virens) is a major top-predator fish species in the North Sea, and it is commercially important for several European countries, i.e. Germany, France, United-Kingdom and Norway. Recent stock assessments suggest that North Sea saithe Spawning Stock Biomass (SSB), mean weight-at-age (Figure 1) and growth have decreased in recent years (ICES, 2014a). This decrease might affect stock productivity and the sustainability of dependent fisheries (Brander, 2007). Many factors, related to genetic and/or phenotypic plasticity may affect fish growth (Sinclair et al., 2002). Genetic effects may be induced by fisheries (Stokes \& Law, 2000). The resulting changes on growth rate are supposedly slow: $0.1 \%$ per year according to Andersen \& Brander (2009), and therefore might be highlighted only in long-term studies. In contrast, substantial changes related to phenotypic plasticity can be observed on shorter time scales.

Three environmental factors are commonly assumed to affect fish growth: densitydependence (Lorenzen \& Enberg, 2002, Sinclair et al., 2002), temperature (Brunel \& Dickey-Collas, 2010, Baudron et al., 2011), and food availability (Krohn et al., 1997, Gjøsaeter et al., 2009). Density-dependent regulation generally results from an increased intraspecific competition for food at large stock size (Sinclair et al., 2002, Brunel \& Dickey-Collas, 2010). Density-dependent growth was recognized as a common process for marine species (Lorenzen \& Enberg, 2002, Sinclair et al., 2002). Density-dependent effects need to be taken into account while managing species as 
their removal and/or conservation might decrease or increase these effects (Lorenzen \& Enberg, 2002).

Changes in temperature might also affect food availability (Möllmann et al., 2005, Baudron et al., 2011) or have more direct effects on fish physiology. Indeed, there is an optimum temperature for growth (Jennings et al., 2001), which declines with decrease of food rations (Sinclair et al., 2002). In the theoretical case of unlimited food availability, growth would be determined by temperature only (Brett \& Groves, 1979). There is currently insufficient available information to relate saithe growth to environmental changes and density-dependent effects are currently neglected (ICES, 2014a). Hence, regulation through food availability, which is entangled with densitydependence and temperature, needs to be investigated.

Saithe growth may be controlled by food availability, resulting from changes in temperatures, intra- or interspecific competition, and thereby could be linked to densities of mid-trophic level species such as forage fishes (Frederiksen et al., 2006, Engelhard et al., 2014, Plaganyi \& Essington, 2014). These key species have been evidenced to either positively affect predator fish growth (Krohn et al., 1997, Huse et al., 2004, Gjøsaeter et al., 2009, Engelhard et al., 2014) or, on the contrary, negatively affect predator fish abundance through predation of the predators' eggs or larvae (Engelhard et al., 2014). Saithe diet is generally based on forage species among which Norway pout (Trisopterus esmarkii) is of major importance (Bergstad, 1991, Du Buit, 1991, DuBuit, 1996, Engelhard et al., 2014).

In the North Sea, the recent emergence of the highly piscivorous hake (Merluccius merluccius), highlighted by Baudron \& Fernandes (2014) and Cormon et al. (2014), might have impacts on the North Sea ecosystem. These impacts could be direct, e.g. on prey species, or indirect, e.g. on other predator species feeding on similar prey assemblage. Saithe and hake have similar feeding habits, particularly concerning Norway pout (Bergstad, 1991, Du Buit, 1991, DuBuit, 1996). In addition, Cormon et al. (2014) showed an increasing spatial overlap between hake and saithe correlated with Norway pout presence. Therefore, hake emergence might affect Norway pout biomass, which has been declining since 2009 (ICES, 2014a), with a knock-off effect on saithe growth.

In order to understand the potential impacts of hake on saithe population in the North Sea, it appears necessary to first understand the potential relationships between Norway pout biomass and saithe growth characteristics that were never investigated in this area. Norway pout is a short-lived species, and its dynamics are driven by changes in recruitment and/or predation mortality rather than by fishing mortality that is relatively low for this species (ICES, 2014a). The environmental factors driving Norway pout recruitment are highly variable. Predation mortalities 
are exerted on all ages by both saithe and hake (Lambert et al., 2009, ICES, 2014a,b).

Both Norway pout and saithe are northern species with overlapping areas of distribution in the North Sea and Skagerrak (Lambert et al., 2009, ICES, 2014a). However, only adult saithe show spatial overlap with Norway pout. Saithe juveniles are distributed inshore where Norway pout (and adult saithe) are rarely present (ICES, 2014a). Hence, high Norway pout biomass (or saithe abundance) is expected to have only little negative impacts on saithe through predation (or cannibalism) on juveniles, which allows to disentangle top-down and bottom-up effects. In addition, Cormon et al. (2014) showed a positive relationship between Norway pout and saithe probability of presence in the North Sea while Lynam et al. (2015) showed a positive correlation between Norway pout and saithe biomass. For these reasons, it may be reasonable to assume that Norway pout biomass is a suitable descriptor of food available to saithe, particularly when investigating limitation of resources due to potential competition between saithe and hake. Evidencing resource limitation is a requirement to assume competitive interactions between two species (Link \& Auster, 2013). While difficult to highlight at large scale,this process may be evaluated through indirect methods such as the study of relationship between prey availability and predator growth.

Growth characterisation generally involves the determination of the size of an organism (length or weight) in relation to time. Numerous models have been used to describe fish growth, of which the von Bertalanffy Growth Function (VBGF) model is probably the most common (Jennings et al., 2001, Katsanevakis, 2006, Haddon, 2011). VBGF describes an organism's length in relation to its age. It is based on three parameters: (i) an asymptotic length representing the maximum size the organism can reach; (ii) a growth constant representing how swiftly the organism's size converges towards its asymptotic value; and (iii) the theoretical age of an organism of size 0 . The a priori use of the VBGF, even when providing a good description of most fish species growth (Jennings et al., 2001), may be problematic (Katsanevakis, 2006). Particularly, asymptotic length and age-at-size 0 estimations must be extrapolated and might lack biological meaning (Haddon, 2011). Kienzle (2005) recognised the issue of using VBGF for the description of saithe growth, which does not show an asymptotic length. In this context, different characterisations of saithe growth need to be investigated. Finally, to study potential effects of the environment on saithe growth, biologically meaningful growth parameters must be used.

In this study, we investigated the interannual variability of North Sea saithe growth in relation to different biotic and abiotic environmental factors. Saithe growth was first described using annual mean weight-at-age increments. Secondly, the re- 
lationship between saithe length and age was investigated. To this purpose, three models, describing saithe growth through either linear or asymptotic age-length relationships, were considered. Environmental factors considered were (i) main prey availability, represented by the total total biomass of Norway pout, a prey that also represents a major component of hake diet; (ii) density-dependence, represented by saithe abundance; and (iii) temperature.

\section{Material and methods}

\subsection{Data}

\subsubsection{Saithe size-at-age characteristics}

Saithe (Pollachius virens) mean weight-at-age (kg), from age 3 to age 10 (yrs), were extracted from ICES (2014a), over the period 1987-2012. Age-Length Keys (ALK) were compiled on the basis of length measurements and age-reading on otoliths, using both survey and commercial data sources. ALK survey data were collected during the North Sea International Bottom Trawl Survey (IBTS) and subsequently extracted from the International Council for the Exploration of the Sea (ICES) online DAtabase of TRAwling Survey (DATRAS) for the period 1991-2012 (except for 2006 for which data were missing). Data were explored by age for length values and outliers (extreme values considered biologically meaningless) were ignored in subsequent analyses. The final survey database included ALK from ages 2 to 10 years (Table 1).

\subsubsection{Environmental factors}

Annual Norway pout (Trisopterus esmarkii) Total Stock Biomass (TSB) (t), and saithe abundance, in total number of individuals, were extracted from assessment report (ICES, 2014a) for the period 1987-2012. Sea bottom temperatures $\left({ }^{\circ} \mathrm{C}\right)$, measured using Sonde (CTD) devices, were extracted from the ICES Oceanographic online database (OCEAN) at quarter and statistical rectangle $\left(1^{\circ}\right.$ longitude $\times 0.5^{\circ}$ latitude) resolution. Bottom temperatures were averaged annually from 1987 to 2012 over the study area (Figure 2).

\subsection{Saithe growth characteristics}

\subsubsection{Annual mean weight increments}

First, saithe annual mean weight increments were calculated (Equation (1)) for each age using mean weight-at-age data described previously. Because age 2 saithe individuals are not in the North Sea (ICES, 2014a), we did not calculate the annual weight increment between ages 2 and 3 . Age 10 is considered as a plus group (age 10 
and older) by ICES (2014a). Therefore, the calculation of an annual weight increment between age 9 and age 10 was not possible (Table 1 ).

$$
\delta w_{a_{t}}=w_{a_{t}}-w_{a-1_{t-1}}
$$

where $\delta w$ is the annual average weight $(w)$ increment in kilos; $a$ the age in years; and $t$ the time in years.

\subsubsection{Age-length relationship}

Three candidate growth models were fitted to saithe age-length data. First, the traditional von Bertalanffy Growth Function (VBGF) was fitted (Equation (2)). Second, a Verhulst logistic growth model (Equation (3)) was fitted and, third, a more pragmatic linear model was fitted (Equation (4)).

The VBGF model (VB) assumes an asymptotic relationship between length, $l$, and age, $a$, depending upon three parameters: an asymptotic length, $l_{\infty}$, a growth coefficient, $K_{\mathrm{VB}}$, which determines how swiftly length, $l$, converges towards its asymptotic value, and $a_{0}$ which represents the theoretical age at which individuals are of size null.

$$
\left.l_{a}=l_{\infty} \times\left(1-e^{-K_{\mathrm{VB}} \times\left(a-a_{0}\right)}\right)\right)
$$

where $l_{\infty}$ is in centimetres; $K_{\mathrm{VB}}$ in year ${ }^{-1}$; and $a_{0}$ in years.

The logistic model (LG) assumes a sigmoidal relationship between length, $l$, and age, $a$, depending upon three parameters: an asymptotic length, $l_{\infty}$; a relative growth coefficient, $K_{\mathrm{LG}}$; and $a_{i}$, a sigmoidal curve inflection point, which represents the theoretical age at which individuals growth trajectory changes.

$$
l_{a}=l_{\infty} \times \frac{1}{\left.\left(1+e^{-K_{\mathrm{LG}} \times\left(a-a_{i}\right)}\right)\right)}
$$

where $l_{\infty}$ is in centimetres; $K_{\mathrm{LG}}$ in year ${ }^{-1}$; and $a_{i}$ in years.

The linear model (LM) assumes that within the range of data available, length, $l$, is linearly related to age, $a$, depending upon an intercept, $l_{0}$ which represents the length at age 0 and a regression coefficient, $K_{L M}$, here representing growth.

$$
l_{a}=l_{0}+K_{\mathrm{LM}} \times a
$$

where $l$ is in centimetres; $a$ in years; and $K_{\mathrm{LM}}$ in centimetres per year.

Age proportions within each year were checked to ensure sufficient and similar representation of the different ages. As different ages represented within a year belong to different cohorts and in order to reduce the cohort-related correlation, the 
three models were fitted for each year separately (ICES, 1991). Therefore, each year was considered as an independent sub-population allowing us to identify potential short-term variations by representing saithe annual average growth (Haddon, 2011) rather than focus on cohort average growth, which may involve longer-term effects. Linear models (Equation (4)) were fitted using linear regression, while asymptotic models (Equations (2) and (3)) were fitted using Non-linear Least Squares (NLS) regression. NLS iterations were optimized using Marquadt's algorithm and starting values set as follows: $K=0.07$ (Jennings et al., 1998); $l_{\infty}=177.1 \mathrm{~cm}$ (Jennings et al., 1998); $a_{0}=-0.8$ years (Froese \& Pauly, 2014); and, $a_{i}=5$ years based on saithe age at first maturity (Froese \& Pauly, 2014, ICES, 2014a). NLS regressions were optimized using R 2.15.3 and nlxb function of $\{\mathrm{nlmrt}\}$ (Nash, 2013). The three candidate model were evaluated based on the comparison of their corrected Akaike Information Criterion (AICc), which is used to compare non-nested models Goodness-of-Fit (GoF) (Burnham \& Anderson, 2002). Differences between all models $\left(\Delta \mathrm{AIC}_{c}\right)$ were calculated and the model with smallest AICc was selected.

\subsection{Effect of the environment}

\subsubsection{Annual mean weight increment analysis}

Generalized Least Squares (GLS) were used to fit the relationships between saithe annual mean weight increment, $\delta w_{a_{t}}$, and environmental factors prevailing during the year of the increment $(t-1)$ as described by Equation (5),

$$
\delta w_{a_{t}} \sim \mu+\beta_{1} \cdot n_{T S B_{t-1}}+\beta_{2} \cdot s_{N B_{t-1}}+\beta_{3} \cdot \Theta_{t-1}+\epsilon_{t}
$$

where $a$ is the age; $t$ the time in years; $\mu$ the intercept; $\beta_{1}, \beta_{2}$ and $\beta_{3}$ are the coefficients associated to Norway pout TSB $\left(n_{T S B}\right)$ representing food availability, saithe abundance $\left(s_{N B}\right)$ representing density dependence and mean bottom temperature $(\Theta)$, respectively; and $\epsilon$ the residual error. Residuals were checked for time autocorrelation using correlograms.

When significantly autocorrelated, the residuals' error structure could be described by, either an AutoRegressive model (AR) where residuals $\left(\epsilon_{t}\right)$, depend upon lagged $(s)$ residuals $\left(\epsilon_{t-s}\right)$; a Moving Average model (MA) where $\left(\epsilon_{t}\right)$ depends upon both random noise indexed at time $t\left(v_{t}\right)$, and its lagged value $\left(v_{t-s}\right)$; or an $\mathrm{Au}$ toRegressive Moving Average model (ARMA), combining both (Zuur et al., 2009). The error structure was determined by examining the autocorrelation and partial autocorrelation functions (Zuur et al., 2009, Groeger et al., 2014). The regression described by Equation (5) was modified to include in the residuals, $\epsilon_{t}$, the suitable time correlation structure chosen among the previously mentioned ones. The GoF of 
the error-structured model was compared to original models based on Akaike Information Criterion (AIC). Equation (6) describes a first order (1,1) ARMA process.

$$
\epsilon_{t}=\phi \cdot \epsilon_{t-1}+v_{t}+\theta \cdot v_{t-1}
$$

where $t$ is the time in years, $\phi$ the AR parameter, $v$ the random noise and $\theta$ the MA parameter. When residuals were not autocorrelated, the regression was equivalent to an Ordinary Least Squares (OLS) regression. Least-squares optimisation was made using Nelder \& Mead (1965) algorithm.

Contribution of the different descriptors was tested using either F-test, when residual errors were not significantly autocorrelated, or Wald-test, when residuals autocorrelation was taken into account. Variables with the highest p-values were dropped one by one to select significant variables by backward elimination $(\alpha<0.05)$. As multiple tests were carried out (one test per mean weight-at-age increment), pvalues were adjusted using Holm correction (Wright, 1992) to keep the family-wise type I error rate at level $\alpha=0.05$. In total six regression models, from age increment 3-4 $\left(\delta w_{4}\right)$ to age increment 8-9 $\left(\delta w_{9}\right)$, with different descriptor coefficients and descriptor significance per model, were fitted. Regression residuals, after autocorrelation was taken into account if necessary, were tested for trends, normality and homoscedasticity.

\subsubsection{Growth coefficient analysis}

The study of environmental effects focused on temporal variations of saithe growth coefficient, $K$, as other growth parameter might result from extrapolation or are biologically meaningless (Kienzle, 2005, Haddon, 2011). First, the trends of the three environmental variables $\left(n_{T S B}, s_{N B}\right.$ and $\left.\Theta\right)$ were compared to annual $K$ trends estimated with selected growth models. Pearson correlation coefficients $(r)$ between $K$ and environment time-series were calculated. To study the short-term variations of growth, we used a 1 year time-lag for the exploration of environmental effects. Thus, we focused on short-term environmental effects (conditions prevailing the year before) on saithe annual average growth. Secondly, the relationships between $K$ and the environment were investigated with regression techniques similarly to annual mean weight-at-age increments (see section 2.3.1). Regression residuals were checked for autocorrelation, resulting in the error term potentially including adequate ARMA model (Equation (6)). Contribution of the different descriptors was tested using either F-test, when no significant time autocorrelation was found, or Wald-test, otherwise. Significant variables were selected by backward elimination $(\alpha<0.05)$. Regression residuals, after autocorrelation was taken into account if necessary, were tested for trends, normality and homoscedasticity. 


\section{Results}

\subsection{Saithe growth characteristics}

Trends in mean weight-at-age annual increment showed a general decrease for saithe (Pollachius virens) of all ages between 1988 and 2000 (Figure 3). In addition, weights-at-age increments of the older fish were subject to large interannual variations.

Based on corrected Akaike Information Criterion (AICc) metrics, saithe agelength relationship was generally best described by a logistic growth model (Table 3). The three candidate models, the linear model (LM), the logistic model (LG) and the von Bertalanffy Growth Function (VBGF) model (VB), after being adjusted to our range of data, were not equally meaningful in biological terms. The pragmatic LM model, which assumed an infinite growth (no asymptote), estimated growth parameters in a biologically meaningful range with length-at-age $0, l_{0}$, ranging from $16.41 \mathrm{~cm}$ to $30.41 \mathrm{~cm}$ and $K_{L M}$ ranging from a length increase per year of $4.73 \mathrm{~cm}$ to $8.12 \mathrm{~cm}$ (Table 2). By contrast, the VB model, which builds on ecological theory, led to biologically meaningless estimations of $l_{\infty}$ (median $l_{\infty}>80000 \mathrm{~m}$ ). In comparison, $l_{\infty}$ estimated using LG model were more realistic (median $l_{\infty}=165 \mathrm{~cm}$ ) even if estimates for 5 years $(1998-2000,2003,2004)$ were also meaningless (maximum $l_{\infty}>$ $260000 \mathrm{~m}$ ). These extreme values of $l_{\infty}$ must be caused by the age range of our data which does not cover completely saithe lifespan (Cohen et al., 1990, 25 years old), thus not allowing to estimate the asymptotic plateau.

The comparison of the three models Goodness-of-Fit (GoF) highlighted a better fit of LG models that had the smallest AICc for all years except in 2010, for which VB model had the best fit (Table 3). The LM and VB models had similar GoF, except for years 2008, 2010 and 2011. In order to model saithe growth consistently over years, and based on the models' biological meaningness and GoF, the logistic model was selected as the best descriptor of saithe growth (Figure S1). Saithe growth coefficient $\left(K_{L G}\right)$ globally decreased from 1991 to 2004. At finer scale, $K_{L G}$ decreased (1991-1992; 1996-2000; 2002-2004) and increased (1992-1996; 2000-2002) alternatively (Figure 4). From 2004 to 2011, there was a general increase of $K_{L G}$ except in 2009. The increase in $K_{L G}$ observed from 2009 until 2010 was consistent with that of $K_{V B}$, the growth coefficient of VB that had a better fit for this particular year, thereby confirming that the use of the LG model in 2010 did not affect general trends of annual saithe growth coefficient. Finally, $K_{L G}$ started to decrease again from 2011 to 2012. General trends were consistent between all three $K$ estimates (Figure 4) which comforted us in the trends observed (Figure 4). 


\subsection{Environmental effects}

There was evidence that environmental factors, particularly Norway pout (Trisopterus esmarkii) biomass and saithe abundance, affected annual average growth of saithe. Indeed, $K_{L G}$, was found to be negatively correlated (with a 1 year time lag) with saithe total abundance $\left(s_{N B}, r=-0.67\right.$, Figure $\left.5 \mathrm{a}\right)$ and, to a smaller extent, with temperature $(\Theta, r=-0.13$, Figure $5 \mathrm{c})$. The correlation was positive with Norway pout biomass $\left(n_{T S B}, r=0.41\right.$, Figure $\left.5 \mathrm{~b}\right)$. These effects were confirmed by regression analyses of $K_{L G}$ against the environment which highlighted negative density-dependent effects and positive food availability effects on saithe annual average growth with a time lag of 1 year (Table 4). Temperature, which showed little variations over the studied time period (Figure 5c) was not significantly related to $K_{L G}$ $(\alpha=5 \%)$. In addition, $K_{L G}$ observed time-series comparison with fitted time-series i.e. predicted from models including significant environmental factors, indicated a relatively smoother estimation of $K_{L G}$, particularly after 2003 (Figure 6).

Density-dependence and prey availability explained together $46.79 \%$ of the model deviance (not shown). When saithe abundance increased by 659000 individuals, saithe annual average growth, $K_{L G}$, dropped by 0.01 in the following year. Likewise, a $503000 \mathrm{t}$ increase of Norway pout total biomass led to a $K_{L G}$ increase of 0.001 in the following year. Density-dependent effects on saithe annual average growth were strong and were the main driver of $K_{L G}$ trends explaining $29.67 \%$ of deviance against $17.12 \%$ deviance explained by food availability. Graphical observations of different effects may suggest that food availability becomes a limiting factor only when density-dependence is reduced (Figure 7). To summarise, saithe grew slower when density-dependence was higher independently of the food available. However, when density-dependence was reduced $\left(s_{N B}<200000 \mathrm{t}\right)$ saithe tended to grow faster when more food was available.

Density-dependence was the only environmental factor which had a significant effect on saithe annual mean weight-at-age increment (Table 4). In addition, this negative effect was limited to annual weight increment between ages 5-6 $(\delta w 6)$ and ages $6-7(\delta w 7)$.

\section{Discussion}

In this study, we found that, given the limitations of our data (older age missing), saithe (Pollachius virens) growth is best described by a logistic relationship between age and length. In addition, density-dependence and food availability had, respectively, negative and positive significant effects on saithe growth, while temperature was never found significant. 
The generally poor performance of the von Bertalanffy Growth Function (VBGF) to model saithe annual growth in terms of Goodness-of-Fit (GoF), as well as the lack of biological meaning of some of the growth parameters estimated, confirms the unsuitability of the VBGF to model saithe growth where the range of age-length data is generally located well away from the asymptotic plateau (Kienzle, 2005). The non-asymptotic behaviour of saithe growth curve, within our observation window, is confirmed by the suitability of the linear model to describe saithe growth, which globally performed similarly to the VBGF model. The difficulties to estimate $l_{\infty}$ may also question the suitability of the logistic model, which is asymptotic as well. However, the high GoF of the logistic model when fitted to saithe age-length data and the reasonable range of the estimated parameters confirm its suitability. The yearlybased estimation, instead of the cohort-based estimation often used in growth studies, presents the advantage of reducing temporal correlation (ICES, 1991), thus allowing to consider each year's populations as independent. This reduces the age-related correlation (different ages represented within a year belong to different cohorts) and enhances the focus on short-term environmental effect by averaging saithe growth for each year.

Even if the absolute value of the estimated growth coefficients, $K$, cannot be directly compared, as not representing growth in the same way (see Equations (2) to (4)), the comparison of their time trends is possible. This comparison reveals consistent trends independently of the model used to describe saithe growth. Particularly, a growth increase beginning in the second half of the 2000's can be observed in $K$ time-series resulting from linear, logistic and VBGF estimation as well as in the mean weight increments of the younger ages $(\delta w 4, \delta w 5, \delta w 6)$. Growth coefficient $K_{L G}$ was estimated using a logistic model, selected as the best model to describe saithe annual average growth. $K_{L G}$ shifted in 2004 from a decreasing to an increasing trend. This trend shift coincides with the inception of three species management plans within EU-Norway agreement: North Sea saithe, Northern hake (Merluccius merluccius) and North Sea cod (Gadus morhua).

This coincidence might result from fishing pressure reduction (Engelhard et al., 2015), although the link is not straightforward. The different management plans, when successful, must result in abundance and/or biomass increase of the targeted species (saithe, hake and cod). In this context, significance of the negative densitydependence effects would suggest that the increase in saithe biomass (due to a decrease in fishing mortality) should, according to our result, lead to a decrease in saithe growth, which is just opposite to the observed trend. There are two explanations to this apparent paradox. First, the effects of management plans on fishing mortality and stock abundance are unlikely to be instantaneous, particularly in a changing 
environment context, to a more or less fast actual abundance and/or biomass increase depending on species resilience (Miller et al., 2010). Second, management plans may first have an impact on young individuals which will increase the average growth rate of saithe in the first years before leading to decline. These mid-term effects may be confirmed by $K_{L G}$ decreasing trend starting in 2010. However, fishing mortality alone is not always sufficient to explain growth as environmental factors might influence recruitment and dynamics as well as growth in shorter terms.

Considering short-term effects (one year), almost half of $K_{L G}$ temporal variation was significantly explained by density-dependence, represented by saithe abundance, and food availability, represented by Norway pout (Trisopterus esmarkii) total biomass. The opposite direction of density-dependence and food availability effects are consistent with ecological theory (Jennings et al., 2001, Cury et al., 2003) and confirm the entanglement of these two variables (Sinclair et al., 2002, Lorenzen \& Enberg, 2002). The significance of density-dependence effects on ages 5-6 increments $(\delta w 6)$ and ages 6-7 increments $(\delta w 7)$ may be related to changes in the amount of energy allocated to somatic growth caused by maturation (Brett \& Groves, 1979, Day \& Taylor, 1997), which occurs between age 4 and age 5 for saithe (ICES, 2014a). In this case, we would have expected older ages increments to have significant relationship with density-dependence as well. The lack of observable density-dependent effects could result from the high variability of the older ages annual mean weight increments and suggest that annual mean weight-at-age increments, particularly for the older ages, were too variable to be good descriptor of saithe growth.

The negative correlation between temperature and $K_{L G}$ may suggest that annual mean temperatures are over the growth optimum (Brett \& Groves, 1979). The absence of significant effects of temperature on saithe growth might be explained by the narrow range of temperature variations experienced by the North Sea saithe population in the last 20 years. Because of the limited length of the times series available, and the fact that we study effects at the large scale of the whole North Sea, the best way to investigate temperature effects on saithe growth would be to conduct a study of spatial variation in growth characteristics at a broader geographical scale e.g. across the North Sea, the Northeast Arctic, and the Faroe Islands populations. Such comparisons would be of great interest as these saithe populations all overlap with Norway pout distribution (Lambert et al., 2009). Larger coverage might allow to study the interactions between temperature, density-dependence and food availability, which are particularly meaningful when studying growth (Brett \& Groves, 1979, Sinclair et al., 2002, Brunel \& Dickey-Collas, 2010). Also, a study of saithe growth based upon cohorts instead of years, as was done for haddock (Melanogrammus aeglefinus) in the North Sea (Baudron et al., 2011), or using asymptotic/maximum 
body-size (Baudron et al., 2014) might highlight temperature effects.

The greater effect of density-dependence relative to food availability may indicate that Norway pout alone is not a sufficient descriptor of food availability and that other forage species may be of importance. For instance, euphausiids which are high energetic value preys (Pedersen \& Hislop, 2001) and which were recorded as an important prey for saithe in the North Sea (Bergstad, 1991, Du Buit, 1991) may have an impact on saithe growth (Carruthers et al., 2005). However, the significant effect of Norway pout biomass, which increased from 2004 and decreased from 2009 (ICES, 2014a), on saithe growth indicates that Norway pout is a key species for saithe and confirms previous studies results (Cormon et al., 2014, Lynam et al., 2015). This reinforces the assumption of bottom-up processes regulating growth of North Sea saithe and, combined with density-dependence effects might confirm an increasing (intra- or interspecific) competition for food resource.

Finally, this study shows an effect of the forage fish availability on predator growth. Similar results were obtained in past studies investigating the interactions between capelin (Mallotus villosus) and cod (Northwest Atlantic cod, Krohn et al. (1997); Barent Sea cod, Gjøsaeter et al. (2009)) or sandeel (Ammodytes sp.) and their predators in the North Sea (Engelhard et al., 2013). Regarding, North Sea saithe, no evidence on dependency of its main fish preys was reported before. However, Carruthers et al. (2005) showed a relationship between euphausiids abundance and saithe body condition in the Scotian Shelf. It is the first time that such processes are highlighted for North Sea saithe and Norway pout. This is particularly relevant to anticipate the ecological effect of the emergence of a potential competitor, such as hake (Baudron \& Fernandes, 2014, Cormon et al., 2014), on well-established species such as North Sea saithe. Indeed, the emergence of another top-predator in the North Sea might affect food availability trough predation and, according to the results obtained here, indirectly impact the growth of its competitors, such as saithe.

In this context, the emergence of hake in the North Sea might partially explain the decreasing saithe growth, as Norway pout is also an important ingredient of hake diet shown (ICES, 2014b). In addition, the significant relationship between Norway pout and saithe growth may push forward the saithe and hake competitive interaction hypothesis recently suggested by Cormon et al. (2014) by highlighting a limitation of their common resource. Therefore, these results provide a further step towards a global understanding of the trophic-related processes involved at the population level in a large marine exploited ecosystem such as the North Sea, in addition to their specific interest for saithe population and/or fisheries. 


\section{Acknowledgements}

The authors acknowledge gratefully financial support from France Filière Pêche without which this study could not have been conducted. The authors would also like to thank the International Council for the Exploration of the Sea (ICES) for providing all survey data used in this study, and Florian Tiedemann for the R support. Finally, we are indebted to the thoughtful comments of G. Engelhard, N. Hintzen and one anonymous referee who helped to improve the initial manuscript. 
Table 1: Overview of population size characteristics data, their units, and their age and time coverage. *2006 year is missing.

\begin{tabular}{lccc}
\hline Data & Units & Age & Time \\
\hline Mean weight-at-age & $\mathrm{kg}$ & $3-10$ & $1987-2012$ \\
Annual mean weight increment & $\mathrm{kg}$ & $4-9$ & $1988-2012$ \\
Length-at-age & $\mathrm{cm}$ & $2-10$ & $1991-2012^{*}$ \\
\hline
\end{tabular}

Table 2: Parameters estimates distribution depending on growth model used.

\begin{tabular}{crrr}
\hline Estimate parameter & Minimum & Median & Maximum \\
\hline Linear model, Equation (4) & & & \\
$l_{0}$ & 16.41 & 22.40 & 30.41 \\
$K_{\mathrm{LM}}$ & 4.73 & 6.47 & 8.12 \\
\hline Logistic model, Equation (3) & & \\
$a_{i}$ & 2.62 & 8.88 & 138.40 \\
$K_{\mathrm{LG}}$ & 0.10 & 0.18 & 0.39 \\
$l_{\infty}$ & 82 & 165 & $26.7 \mathrm{e} 06$ \\
\hline von Bertalanffy Growth Function model, Equation $(2)$ \\
$a_{0}$ & -6.10 & -3.14 & -0.93 \\
$K_{\mathrm{VB}}$ & $3.7 \mathrm{e}-07$ & $7.6 \mathrm{e}-07$ & 0.16 \\
$l_{\infty}$ & 95.00 & $8.4 \mathrm{e} 06$ & $17.6 \mathrm{e} 06$ \\
\hline \multicolumn{4}{c}{}
\end{tabular}


Table 3: Differences of $\mathrm{AIC}_{c}\left(\Delta \mathrm{AIC}_{c}\right)$ by pairs of model (between brackets). $\Delta \mathrm{AIC}_{c}(1 / 2)=$ $\mathrm{AIC}_{c}$ (model 1) - $\mathrm{AIC}_{c}$ (model 2). LM: linear model. LG: logistic model. VB: von Bertalanffy Growth Function model.

\begin{tabular}{rrrr}
\hline Year & $\Delta \mathrm{AIC}_{c}(\mathrm{LM} / \mathrm{LG})$ & $\Delta \mathrm{AIC}_{c}(\mathrm{LM} / \mathrm{VB})$ & $\Delta \mathrm{AIC}_{c}(\mathrm{LG} / \mathrm{VB})$ \\
\hline 1991 & 100.17 & 5.70 & -94.47 \\
1992 & 281.86 & -1.00 & -282.86 \\
1993 & 111.92 & -1.01 & -112.92 \\
1994 & 143.85 & -1.00 & -144.85 \\
1995 & -5.51 & -0.67 & 4.83 \\
1996 & 121.04 & -1.00 & -122.04 \\
1997 & 247.85 & -1.01 & -248.85 \\
1998 & 348.21 & -1.00 & -349.22 \\
1999 & 560.41 & -1.00 & -561.42 \\
2000 & 239.14 & -1.00 & -240.15 \\
2001 & 212.69 & -1.00 & -213.70 \\
2002 & 122.59 & -1.00 & -123.60 \\
2003 & 533.72 & -1.01 & -534.73 \\
2004 & 615.62 & -1.00 & -616.62 \\
2005 & 7.16 & -1.00 & -8.17 \\
2007 & 97.05 & -1.00 & -98.06 \\
2008 & 71.49 & 74.55 & 3.05 \\
2009 & 31.93 & 3.45 & -28.49 \\
2010 & 989.94 & 1222.62 & 232.68 \\
2011 & 1304.48 & 672.73 & -631.74 \\
2012 & 358.49 & 2.41 & -356.08 \\
\hline
\end{tabular}


Table 4: Significant relationships of North Sea saithe growth characteristics with environmental variables. Descriptor variables are noted $n_{T S B}$, for Norway pout total biomass; $s_{N B}$, for saithe abundance; and $\Theta$, for temperature. ACF indicates the autocorrelation structure. *Pvalues were obtained after Holm adjustment concerning $w_{a}$.

\begin{tabular}{lcrrr}
\hline Response & Descriptor & ACF & Coefficient & Pvalue* \\
\hline Annual mean weight-at-age increment $\left(\delta w_{a}\right)$ & \\
$\delta w_{6}$ & $s_{N B}$ & None & $-1.57 \mathrm{e}-06$ & $p<0.05$ \\
$\delta w_{7}$ & $s_{N B}$ & None & $-2.21 \mathrm{e}-06$ & $p<0.05$ \\
Growth coefficient $\left(K_{L G}\right)$ & & \\
$s_{N B}$ & None & $-6.59 \mathrm{e}-07$ & $p<0.01$ \\
$n_{T S B}$ & None & $5.03 \mathrm{e}-08$ & $p<0.05$ \\
\hline
\end{tabular}




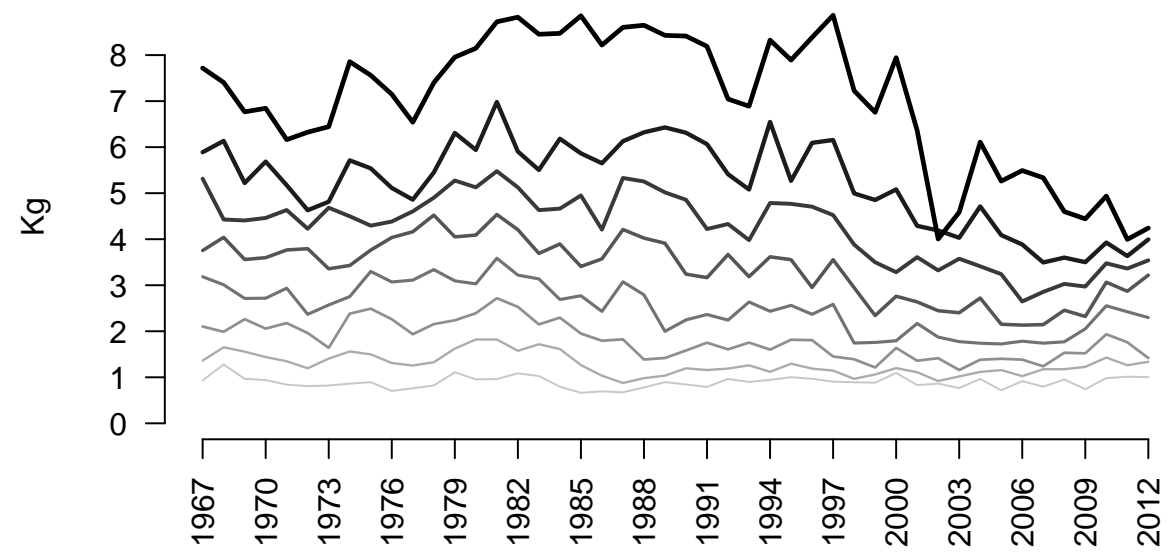

Figure 1: Saithe mean weight-at-age trends from 1967 to 2012. Saithe mean weight-at-age 3 (light grey thin line) to mean weight-at-ages $10+$ (black thick line).

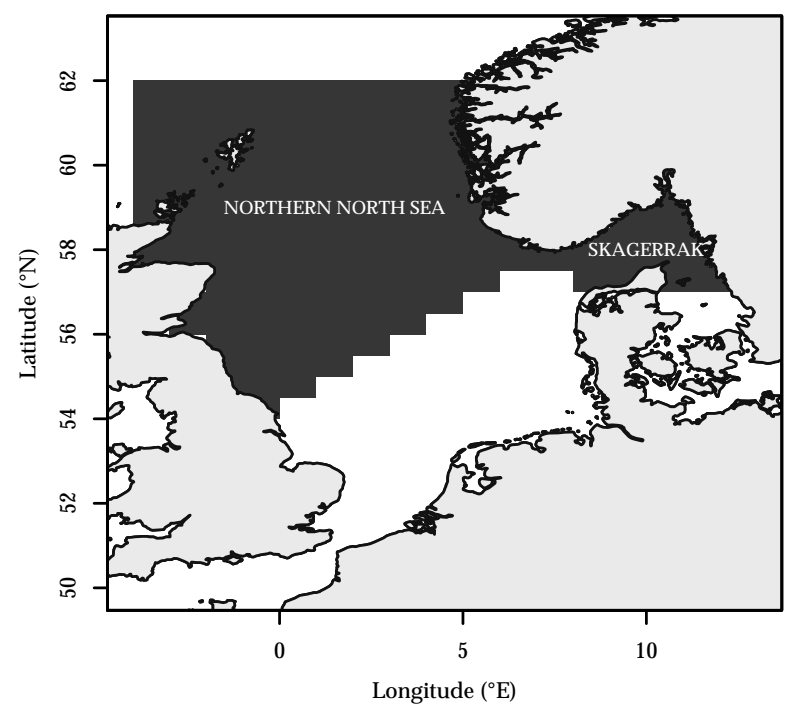

Figure 2: Map of the study area. 


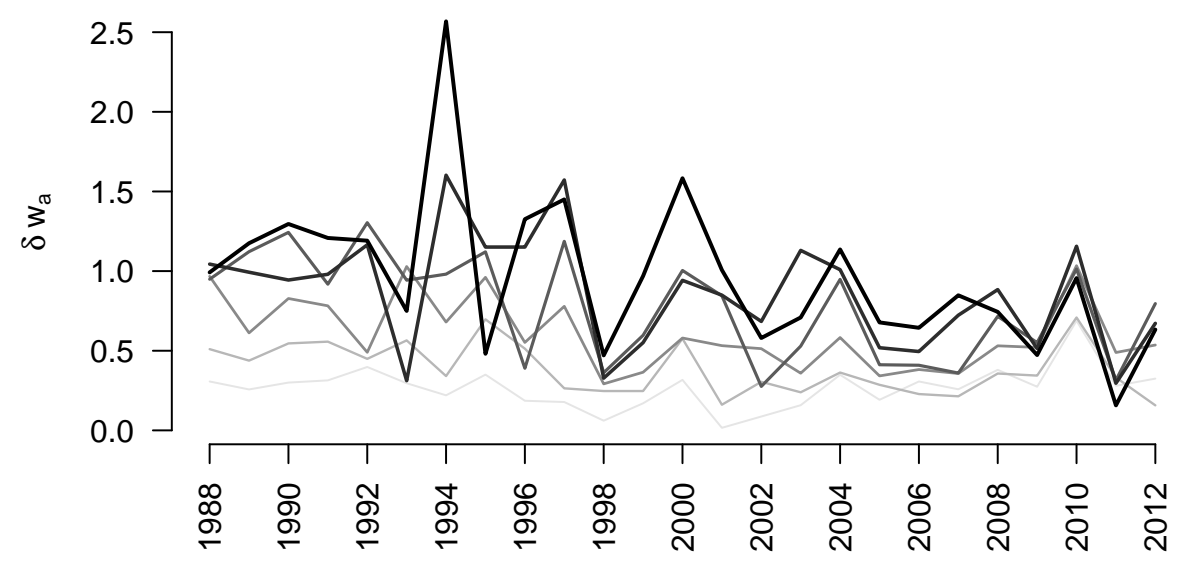

Figure 3: Temporal trends in North Sea saithe annual mean weight-at-age increment $\left(\delta w_{a}\right)$ over the 1988-2012 period. Increments between age 3 and age 4 ( $\delta w_{4}$, light grey thin line) to increments between age 8 and age $9\left(\delta w_{9}\right.$, black thick line).

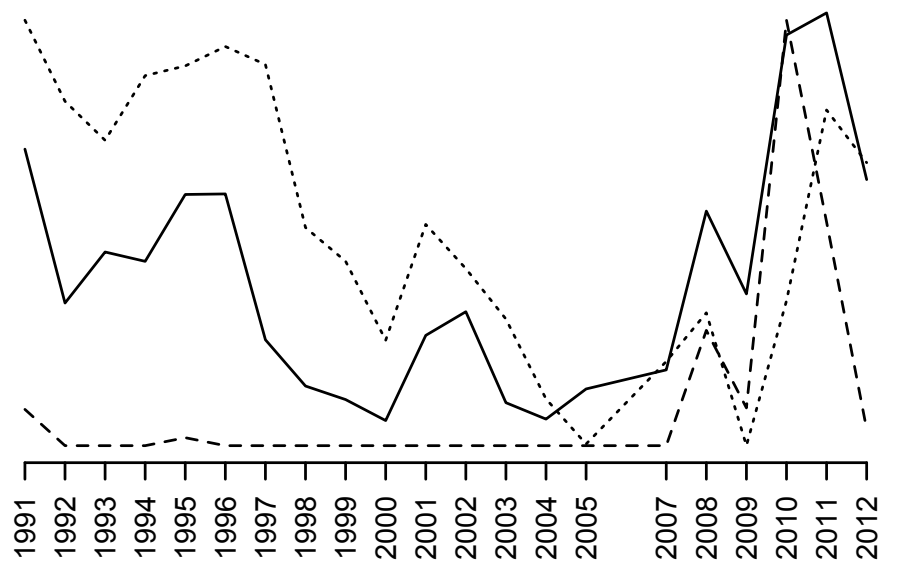

Figure 4: Growth coefficients, K, estimated for period covering 1991 to 2012 using the linear model, the Verhulst logistic growth model and the Von Bertalanffy Growth Function. The dotted line shows the linear model growth coefficient estimates, $K_{L M}$ (Equation (4)); the solid line shows the Verhulst logistic model growth estimates, $K_{L G}$ (Equation (3)); and the dashed line shows the VBGF model estimates, $K_{V B}$ (Equation (2)). Y-axis are not plotted as absolute values of the different growth coefficients are not of interest. 
(a) Density dependence

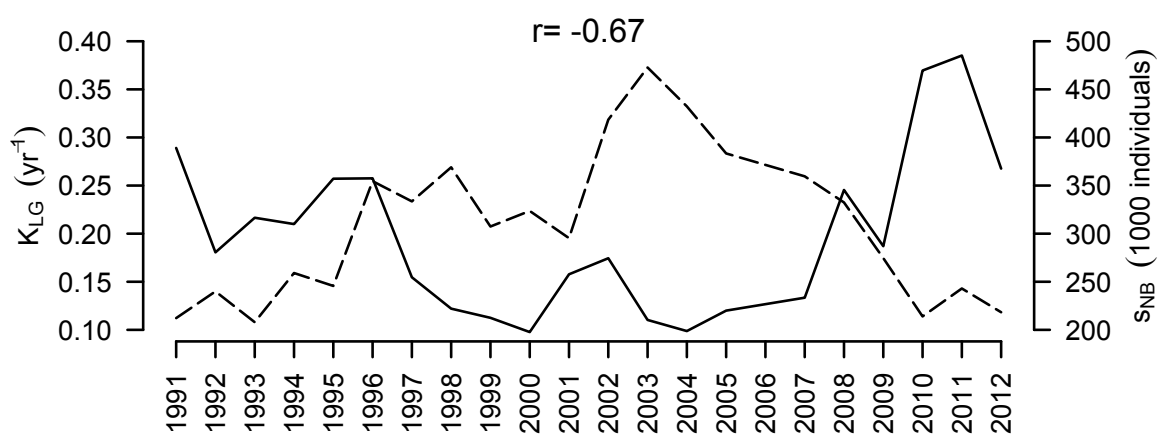

(b) Food availability

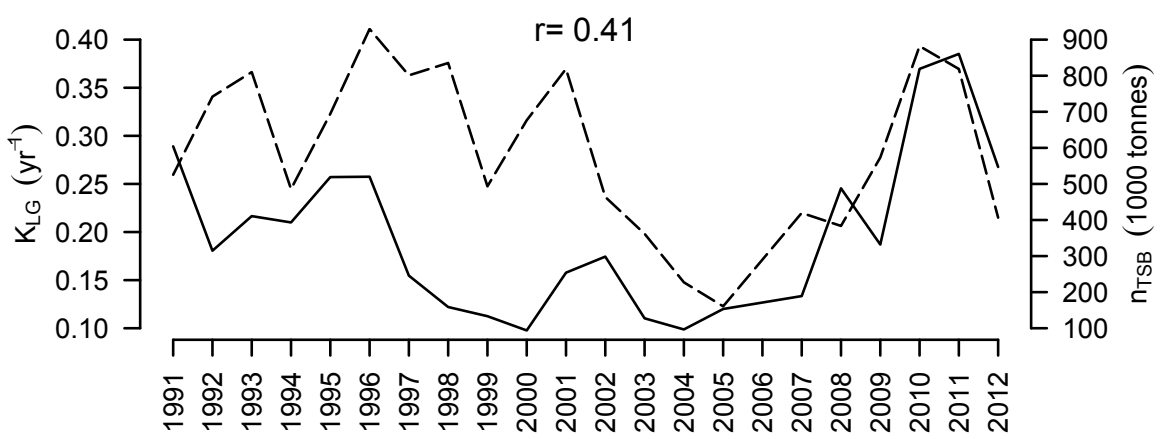

(c) Temperature

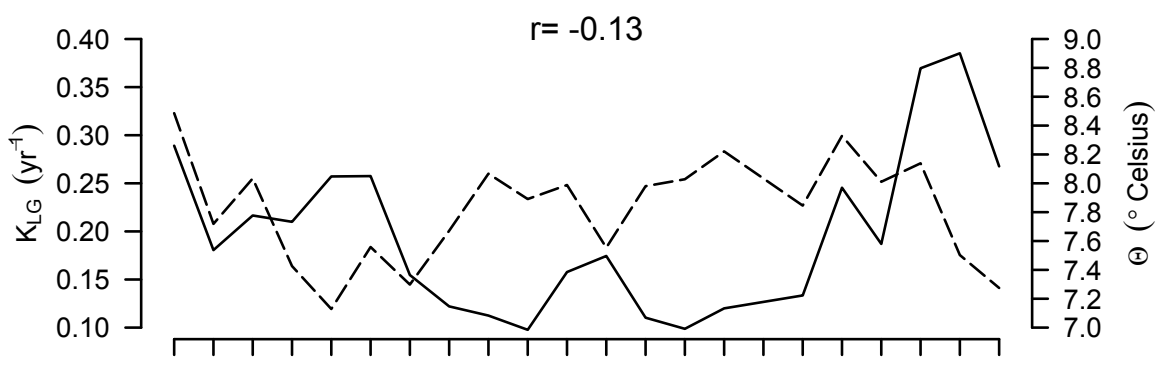

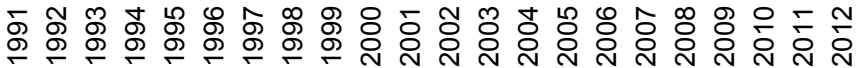

Figure 5: Environmental factors time series from 1991 to 2012 compared to saithe growth coefficient estimates and the corresponding Pearson correlation coefficient $(r)$. Solid lines represent the growth coefficient from logistic growth model, $K_{L G}$; and dashed lines represent the environmental variables of the year before (a) saithe abundance, $S_{N B}$; (b) Norway pout Total Stock Biomass, $n_{T S B}$; and (c) temperature, $\theta$. 


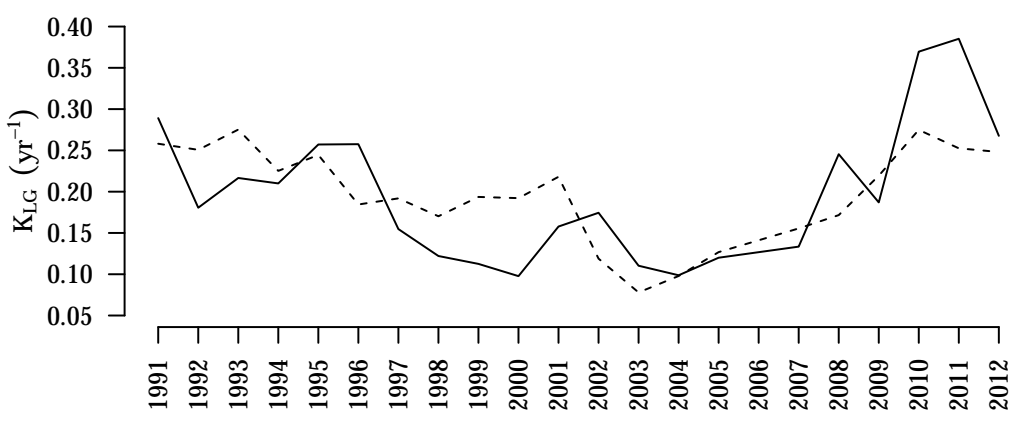

Figure 6: Observed saithe growth coefficient, $K_{L G}$ (solid line), and $K_{L G}$ fitted with models including significant environmental factors (dashed line).

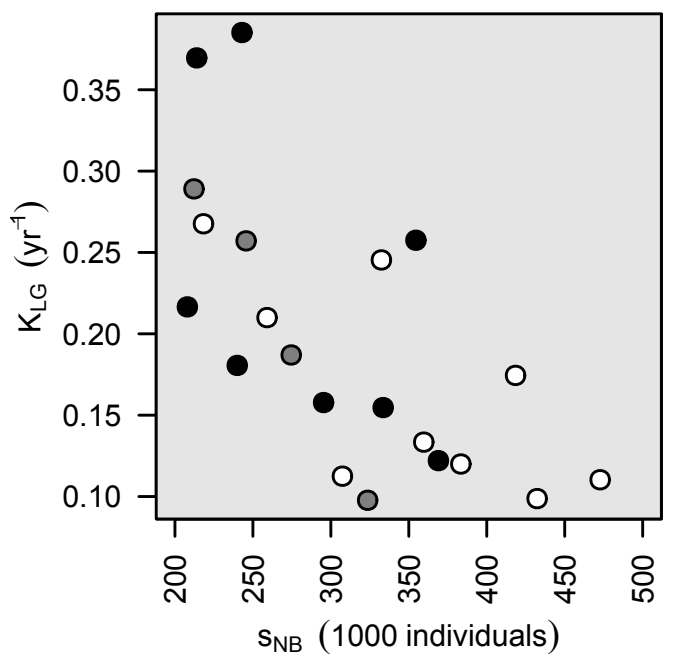

Figure 7: Saithe average growth $\left(K_{L G}\right)$ as function of saithe total abundance $\left(s_{N B}\right)$. Color filling represents Norway pout availability $\left(n_{T S B}\right)$. White: low availability $\left(n_{T S B}<500000 \mathrm{t}\right)$. Grey: medium avialability $\left(500000 \mathrm{t}<n_{T S B}<700000 \mathrm{t}\right)$. Black: high availability $\left(n_{T S B}>700000 \mathrm{t}\right)$. 


\section{Supplementary material}

(a) 1991

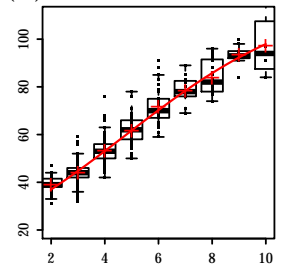

(b) 1992

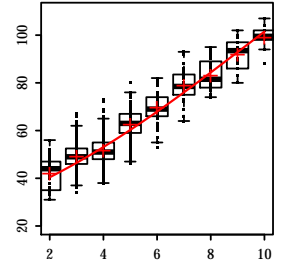

(f) 1996

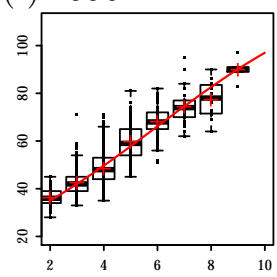

(g) 1997

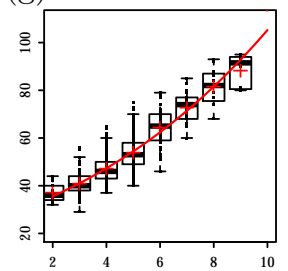

(1) 2002

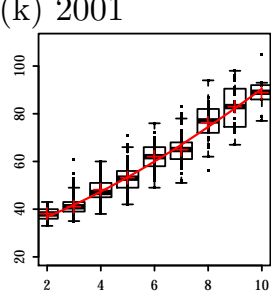

(p) 2007
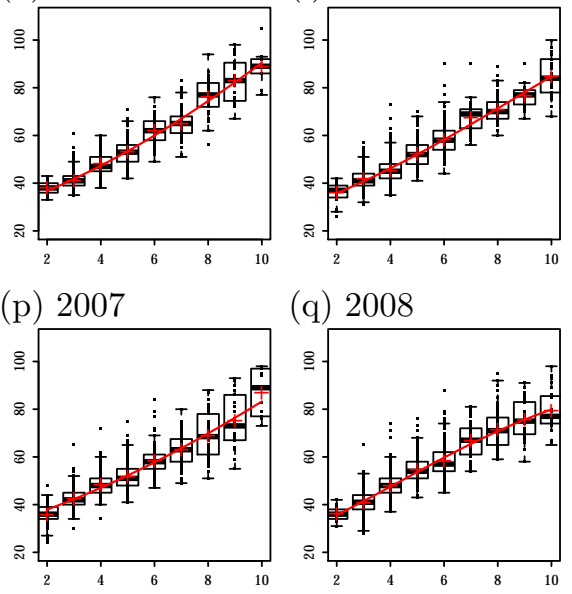

(q) 2008

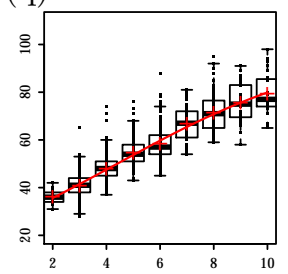

(c) 1993

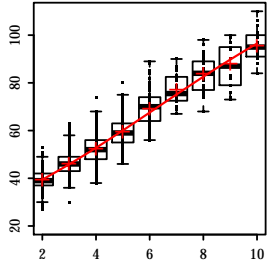

(h) 1998

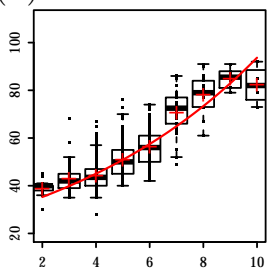

(m) 2003

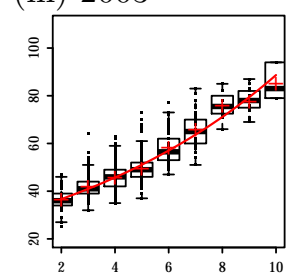

(r) 2009

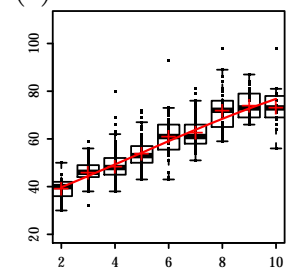

(d) 1994

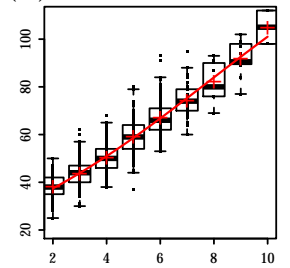

(e) 1995

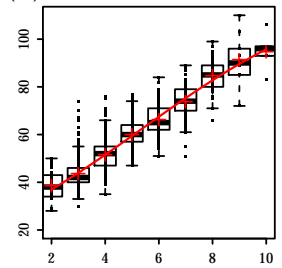

(i) 1999

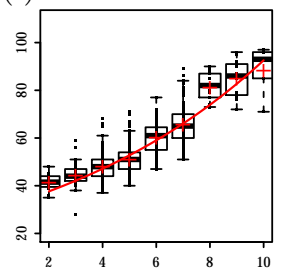

(j) 2000

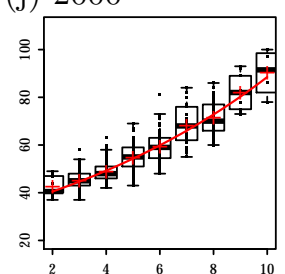

(n) 2004

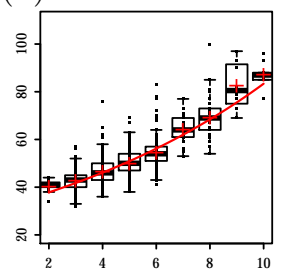

(o) 2005

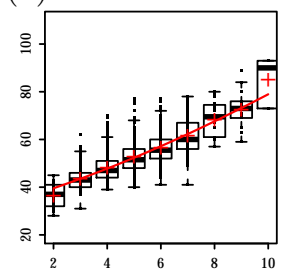

(s) 2010

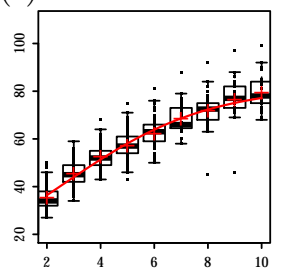

(t) 2011

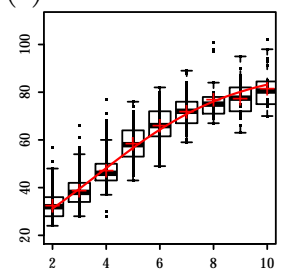

(u) 2012

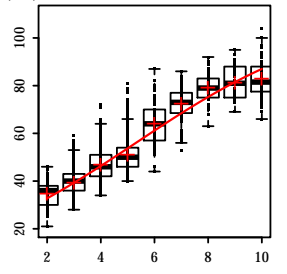

Figure S1: North Sea saithe length measured during the different survey years as function of the age. Red crosses represent mean length-at-age, red lines represent fitted logistic growth curves. 


\section{References}

Andersen KH, Brander K (2009) Expected rate of fisheries-induced evolution is slow. Proceedings of the National Academy of Sciences of the United States of America 106:11657-11660

Baudron AR, Fernandes PG (2014) Adverse consequences of stock recovery: European hake, a new "choke" species under a discard ban? Fish and Fisheries doi: 10.1111/faf.12079

Baudron AR, Needle CL, Marshall CT (2011) Implications of a warming North Sea for the growth of haddock Melanogrammus aeglefinus. Journal of Fish Biology $78: 1874-1889$

Baudron AR, Needle CL, Rijnsdorp AD, Marshall CT (2014) Warming temperatures and smaller body sizes: synchronous changes in growth of North Sea fishes. Global Change Biology 20:1023-1031

Bergstad OA (1991) Distribution and trophic ecology of some gadoid fish of the Norwegian deep. 2. Food-web linkages and comparisons of diets and distributions. Sarsia 75:315-325

Brander KM (2007) The role of growth changes in the decline and recovery of North Atlantic cod stocks since 1970. protectICES Journal of Marine Science 64:211-217

Brett J, Groves T (1979) Physiological Energetics, Academic Press, Elsevier, Amsterdam, vol. 8 of Fish Physiology, chap. 6. pp. 279-352

Brunel T, Dickey-Collas M (2010) Effects of temperature and population density on von Bertalanffy growth parameters in Atlantic herring: a macro-ecological analysis. Marine Ecology Progress Series 405:15-28

Burnham KP, Anderson DR (2002) Model selection and multimodal inference. A pratical information-theoretic approach. 2nd edition. Springer, Berlin

Carruthers EH, Neilson JD, Waters C, Perley P (2005) Long-term changes in the feeding of Pollachius virens on the Scotian Shelf: responses to a dynamic ecosystem. Journal of Fish Biology 66:327-347

Cohen DM, T. I, Iwamoto T, Scialabba N (1990) Gadiform fishes of the world (Order Gadiformes). An annotated and illustrated catalogue of cods, hakes, grenadiers and other gadiform fishes known to date., vol. 125(10) of FAO Fisheries Synopsis. FAO species catalogue. 
Cormon X, Loots C, Vaz S, Vermard Y, Marchal P (2014) Spatial interactions between saithe (Pollachius virens) and hake (Merluccius merluccius) in the North Sea. ICES Journal of Marine Science 71:1342-1355

Cury P, Shannon L, Shin YJ (2003) The functioning of marine ecosystems: a fisheries perspective. Responsible Fisheries in the Marine Ecosystem :103-123

Day T, Taylor PD (1997) Von bertalanffy's growth equation should not be used to model age and size at maturity. American Naturalist 149:381-393

Du Buit MH (1991) Food and feeding of saithe (Pollachius virens) off Scotland. Fisheries Research 12:307-323

DuBuit MH (1996) Diet of hake (Merluccius merluccius) in the Celtic Sea. Fisheries Research 28:381-394

Engelhard GH, Blanchard JL, Pinnegar JK, van der Kooij J, Bell ED, Mackinson S, Righton DA (2013) Body condition of predatory fishes linked to the availability of sandeels. Marine Biology 160:299-308

Engelhard GH, Lynam CP, Garcia-Carreras B, Dolder PJ, Mackinson S (2015) Effort reduction and the large fish indicator: spatial trends reveal positive impacts of recent european fleet reduction schemes. Environmental Conservation 42:227-236

Engelhard GH, Peck MA, Rindorf A, C. Smout S, van Deurs M, Raab K, Andersen KH, Garthe S, Lauerburg RAM, Scott F, Brunel T, Aarts G, van Kooten T, DickeyCollas M (2014) Forage fish, their fisheries, and their predators: who drives whom? ICES Journal of Marine Science 71:90-104

FAO (2003) 2. The Ecosystem Approach to Fisheries. Fisheries Management Technical Guidelines for Responsible Fisheries 4. Suppl. 2, FAO

Frederiksen M, Edwards M, Richardson AJ, Halliday NC, Wanless S (2006) From plankton to top predators: bottom-up control of a marine food web across four trophic levels. Journal of Animal Ecology 75:1259-1268

Froese R, Pauly D (2014) FishBase. URL http://www.fishbase.org, accessed: December 7, 2015

Gjøsaeter H, Bogstad B, Tjelmeland S (2009) Ecosystem effects of the three capelin stock collapses in the Barents Sea. Marine Biology Research 5:40-53 
Groeger JP, Hinrichsen HH, Polte P (2014) Broad-scale climate influences on springspawning herring (Clupea harengus, L.) recruitment in the western Baltic Sea. Plos One 9. 10.1371/journal.pone.008752

Haddon M (2011) Growth of individuals, Chapman \& Hall/CRC, Boca Raton, chap. 9. pp. 215-254

Huse G, Johansen GO, Bogstad L, Gjosaeter H (2004) Studying spatial and trophic interactions between capelin and cod using individual-based modelling. ICES Journal of Marine Science 61:1201-1213

ICES (1991) Report of the Multispecies Assessment Working Group. Part 1. CM 1991/ASSESS:7, ICES

ICES (2012) Report of the Working Group on Multispecies Assessment Methods (WGSAM). CM 2012/SSGSUE:10, ICES

ICES (2014a) Report of the Working Group on the Assessment of Demersal Stocks in the North Sea and Skagerrak (WGNSSK). CM/ACOM:13, ICES

ICES (2014b) Annex 5: North Sea SMS model Key Run. Report of the Working Group on Multispecies Assessment Methods (WGSAM). CM 2014/SSGSUE:11, ICES

Jennings S, Kaiser MJ, Reynolds JD (2001) Marine Fisheries Ecology. Blackwell Publishing, Oxford

Jennings S, Reynolds JD, Mills SC (1998) Life history correlates of responses to fisheries exploitation. Proceedings of the Royal Society B Biological Sciences 265:333339

Katsanevakis S (2006) Modelling fish growth: Model selection, multi-model inference and model selection uncertainty. Fisheries research 81:229-235

Kienzle M (2005) Estimation of the parameters of von Bertalanffy growth function for the main commercial species of the North Sea. Internal report no 05/05, Fisheries Research Services

Krohn M, Reidy S, Kerr S (1997) Bioenergetic analysis of the effects of temperature and prey availability on growth and condition of northern cod (Gadus morhua). Canadian Journal of Fisheries and Aquatic Sciences 54:113-121 
Lambert G, Nielsen JR, Larsen LI, Sparholt H (2009) Maturity and growth population dynamics of Norway pout (Trisopterus esmarkii) in the North Sea, Skagerrak, and Kattegat. ICES Journal of Marine Science 66:1899-1914

Laundré JW, Hernandez L, Lopez Medina P, Campanella A, Lopez-Portillo J, Gonzalez-Romero A, Grajales-Tam KM, Burke AM, Gronemeyer P, Browning DM (2014) The landscape of fear: the missing link to understand top-down and bottom-up controls of prey abundance? Ecology 95:1141-1152

Link JS, Auster PJ (2013) The challenges of evaluating competition among marine fishes: who cares, when does it matter, and what can we do about it? Bulletin of Marine Science 89:213-247

Lorenzen K, Enberg K (2002) Density-dependent growth as a key mechanism in the regulation of fish populations: evidence from among-population comparisons. Proceedings of the Royal Society B Biological Sciences 269:49-54

Lynam C, Helaouet P, Mollmann C, Llope M, Mavor R, Bayliss-Brown G, Stenseth NC (2015) Long-term trends in the biomass of commercial fish in the North Sea: The role of fishing impacts, predator-prey interactions and temperature change. PICES 2015 S:10

Miller K, Charles A, Barange M, Brander K, Gallucci VF, Gasalla MA, Khan A, Munro G, Murtugudde R, Ommer RE, Perry RI (2010) Climate change, uncertainty, and resilient fisheries: Institutional responses through integrative science. Progress in Oceanography 87:338-346

Möllmann C, Kornilovs G, Fetter M, Koster FW (2005) Climate, zooplankton, and pelagic fish growth in the central Baltic Sea. protectICES Journal of Marine Science 62:1270-1280

Nash JC (2013) nlmrt: Functions for Nonlinear Least Squares Solutions. CRAN - R package version 2013-9.25

Nelder JA, Mead R (1965) A simplex method for function minimization. The Computer Journal 7:308-313

Pedersen J, Hislop JRG (2001) Seasonal variations in the energy density of fishes in the north sea. Journal of Fish Biology 59:380-389 
Plaganyi EE (2007) Models for an ecosystem approach to fisheries, vol. 477 of FAO fisheries technical paper. Food and Agriculture Organization of the United Nations, Rome

Plaganyi EE, Essington TE (2014) When the SURFs up, forage fish are key. Fisheries Research 159:68-74

Sinclair AF, Swain DP, Hanson JM (2002) Disentangling the effects of size-selective mortality, density, and temperature on length-at-age. Canadian Journal of Fisheries and Aquatic Sciences 59:372-382

Stokes K, Law R (2000) Fishing as an evolutionary force. Marine Ecology Progress Series 208:307-309

Wright SP (1992) Adjusted p-values for simultaneous inference. Biometrics 48:10051013

Zuur AF, Ieno EN, Walker NJ, Saveliev AA, Smith GM (2009) Mixed Effects Models and Extensions in Ecology with R. Statistics for Biology and Health, Springer, Berlin 